SUPPLEMENT

\title{
Testosterone and doping control
}

\section{Saudan, N Baume, N Robinson, L Avois, P Mangin, M Saugy}

Br J Sports Med 2006;40(Suppl I):i21-i24. doi: 10.1136/bjsm.2006.027482

See end of article for authors' affiliations

......................

Correspondence to: M Saugy, Swiss

Laboratory for Doping Analyses, Institute of Legal

Medicine, Lausanne, Switzerland; martial. saugy@chuv.ch
Background and objectives: Anabolic steroids are synthetic derivatives of testosterone, modified to enhance its anabolic actions (promotion of protein synthesis and muscle growth). They have numerous side effects, and are on the International Olympic Committee's list of banned substances. Gas chromatographymass spectrometry allows identification and characterisation of steroids and their metabolites in the urine but may not distinguish between pharmaceutical and natural testosterone. Indirect methods to detect doping include determination of the testosterone/epitestosterone glucuronide ratio with suitable cut-off values. Direct evidence may be obtained with a method based on the determination of the carbon isotope ratio of the urinary steroids. This paper aims to give an overview of the use of anabolic-androgenic steroids in sport and methods used in anti-doping laboratories for their detection in urine, with special emphasis on doping with testosterone.

Methods: Review of the recent literature of anabolic steroid testing, athletic use, and adverse effects of anabolic-androgenic steroids.

Results: Procedures used for detection of doping with endogenous steroids are outlined. The World AntiDoping Agency provided a guide in August 2004 to ensure that laboratories can report, in a uniform way, the presence of abnormal profiles of urinary steroids resulting from the administration of testosterone or its precursors, androstenediol, androstenedione, dehydroepiandrosterone or a testosterone metabolite, dihydrotestosterone, or a masking agent, epitestosterone.

Conclusions: Technology developed for detection of testosterone in urine samples appears suitable when the substance has been administered intramuscularly. Oral administration leads to rapid pharmacokinetics, so urine samples need to be collected in the initial hours after intake. Thus there is a need to find specific biomarkers in urine or plasma to enable detection of long term oral administration of testosterone.
$\mathrm{T}$ he anabolic steroids are chemical, synthetic derivatives of testosterone modified to enhance the anabolic rather than the androgenic actions of the hormone (fig 1). ${ }^{1}$ Testosterone is a steroid hormone, synthesised in the human body from cholesterol. ${ }^{2}$ It serves distinct functions at different stages of life. During embryonic life, androgen action is central to the development of the male phenotype. At puberty, the hormone is responsible for the secondary sexual characteristics that transform boys into men. Testosterone regulates many physiological processes in the adult male including muscle protein metabolism, sexual and cognitive functions, erythropoiesis, plasma lipid levels, and bone metabolism. ${ }^{3}$

\section{PHARMACEUTICAL ACTION OF ANABOLIC STEROIDS}

Soon after testosterone was isolated in 1935, it was discovered that it is virtually inactive when taken orally. After oral ingestion, testosterone is absorbed from the small intestines and passes via the portal vein to the liver where it is rapidly metabolised, mostly to inactive compounds. ${ }^{45}$ The discovery of testosterone has led to the synthesis of anabolic steroids. Chemical modifications of testosterone have been useful pharmacologically to alter the relative anabolicandrogenic potency, slow the rate of inactivation, and change the pattern of metabolism. ${ }^{6}$ Most oral anabolic-androgenic steroids preparations are $17 \alpha$-alkylated derivatives of testosterone, which are relatively resistant to hepatic degradation. Esterification of the 17 $\beta$-hydroxyl group makes the molecule more soluble in lipid vesicles used for injection and hence slows the release of the injected steroid into the circulation. Commonly used $17 \alpha$-alkyl and $17 \beta$-ester derivatives are shown in fig 2.
Androgenic and anabolic effects of anabolic-androgenic steroids originate from activation of the androgenic receptors. The distinction between these biological effects depends on the organs and target tissues. ${ }^{7}$ Dihydrotestosterone is responsible of the androgenic effect. This steroid is more potent than testosterone because of increased affinity to the androgen receptor. It is formed from conversion of testosterone by the $5 \alpha$-reductase enzyme. ${ }^{6}$ Activity of this enzyme is important in testicles, skin, prostate, intestines, brain, bones, and adipose tissues. Therefore, androgenic effects of anabolic-androgenic steroids predominate in these organs. Anabolic effects will concern organs as muscles, bones, the heart and kidneys. These organs possess little $5 \alpha$-reductase activity and thus anabolic-androgenic steroids, particularly testosterone, induce protein synthesis, muscle fiber development, erythropoiesis, and stimulation and inhibition of bone growth. ${ }^{8}$ In addition, anabolic steroids displace glucocorticoids from glucocorticoid receptors and inhibit muscle protein catabolism, leading overall to an anabolic or muscle building effect. ${ }^{9}$

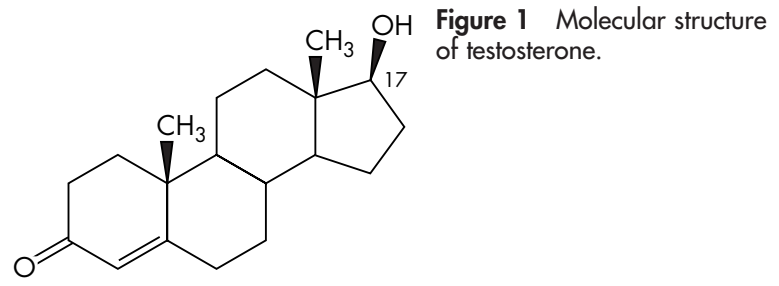

Abbreviations: DHEA, dehydroepiandrosterone; IOC, International Olympic Committee; IRMS, isotopic ratio mass spectrometry; T/E, testosterone to epitestosterone (ratio); WADA, World Anti-Doping Agency 


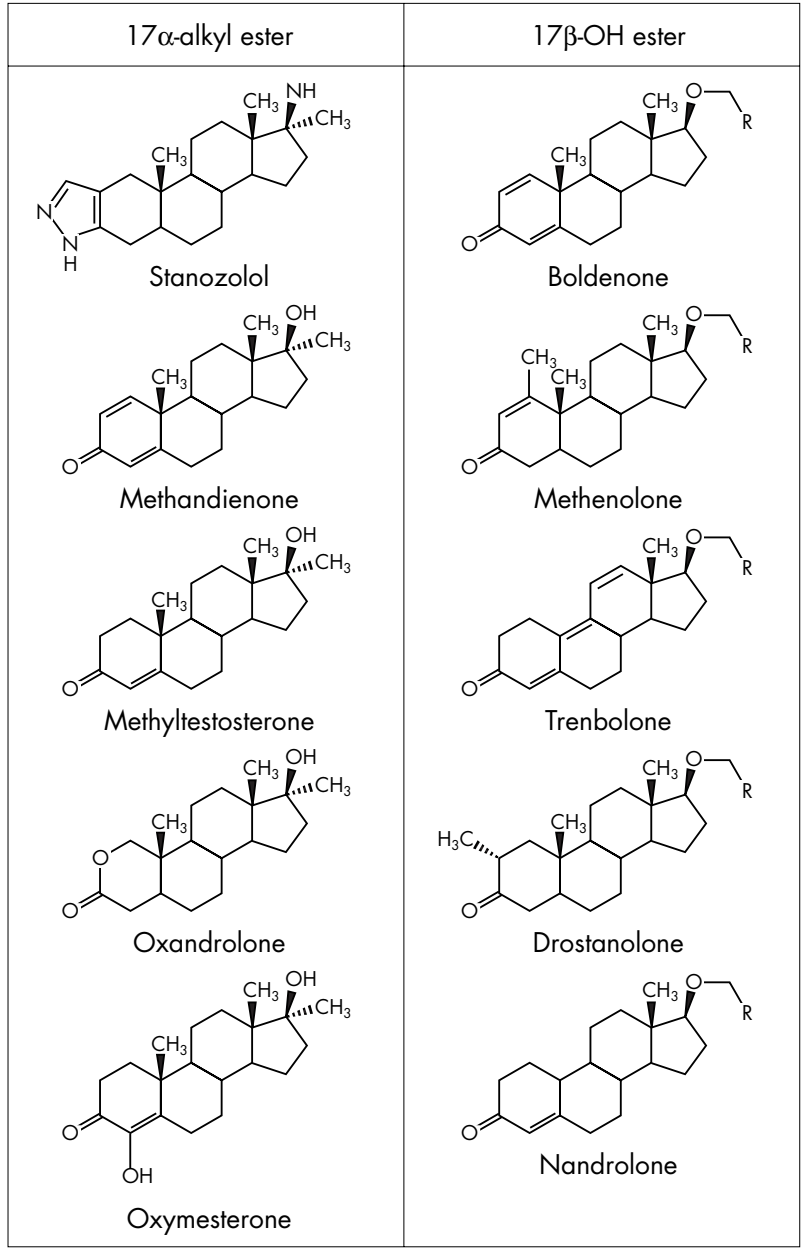

Figure 2 Anabolic-androgenic steroids: molecular structure of common $17 \alpha$-alkyl and $17 \beta$-ester derivatives.

\section{THERAPEUTIC AND ADVERSE EFFECTS OF ANABOLIC-ANDROGENIC STEROIDS}

A number of clinical studies using a variety of experimental designs have shown that the potent anabolic effects of anabolic-androgenic steroids have positive benefits for various patient populations. Physiological replacement doses of testosterone have been used therapeutically to stimulate sexual development in cases of delayed puberty and in cases in which the testicles have been surgically removed, either because of physical injury or because of testicular tumour. ${ }^{8}$ The major clinical use of anabolic steroids is to inhibit the loss of protein and aid muscle regeneration after major surgery. ${ }^{10}$

As anabolic-androgenic steroids have effects in several organ systems, multiple side effects can be observed. ${ }^{11}{ }^{12}$ The frequency of occurrence and severity of side effects are quite variable and depend on numerous factors such as the type of drug, dosage, duration of use, and the individual sensitivity of the response. The potential adverse effects of anabolicandrogenic steroids can be divided into the following categories: cardiovascular, hepatic, endocrine/reproductive, psychological, and tendon injury. ${ }^{13}$

\section{USE OF ANABOLIC-ANDROGENIC STEROIDS BY ATHLETES}

Information on doses and modes of administration of anabolic-androgenic steroids used by athletes to increase their performances is relatively sparse. ${ }^{13}$ It is known that bodybuilders follow a typical pattern called "stacking", based on administration of several oral and injectable anabolic- androgenic steroids during cycles lasting 4-12 weeks. The advantage of this practice has been demonstrated recently. ${ }^{12}$ The drug dosages range from $250 \mathrm{mg}$ to $3500 \mathrm{mg}$ per week and are therefore up to 40 times the recommended therapeutic dosage. ${ }^{14}$ However, some studies have described the effect of polypharmacy practice at therapeutic doses in weight lifters, ${ }^{15}$ and endurance and sprint athletes. ${ }^{16}$

Psychologically, administration of anabolic-androgenic steroids may affect behaviour. Increased testosterone levels in the blood are associated with masculine behaviour, aggressiveness, and increase of sexual desire. ${ }^{17}$ Increased aggressiveness might be beneficial for athletic training, but might also lead to overt violence outside the gym or the track. Other side effects of anabolic-androgenic steroids are euphoria, confusion, sleeping disorders, pathological anxiety, paranoia, and hallucinations. Some of these psychological effects could be beneficial for athletes by improving their performance. Indeed, it is more and more often suggested that the intake of small doses of anabolic-androgenic steroids, particularly testosterone, could lead to a lower fatigue levels, a better recovery, and therefore to higher training charge, and finally to a faster increase in physical performance. In a recent controlled study including a placebo group, the effect of multiple oral doses of testosterone undecanoate on mood state during one month of intense endurance training was assessed. ${ }^{18}$ It emerged that multiple oral intake of testosterone undecanoate could have an impact on recovery from physical strain in a hard training period. In some cases, however, it appeared that mood changes was the result of a placebo effect.

\section{ANABOLIC STEROID TESTING Background}

The medical commissions of major international sport federations and of the International Olympic Committee (IOC) have been concerned over the misuse of doping agents in the sports community since the beginning of the 1970s. At that time, these commissions developed a dope control procedure whose fundamental elements are still valid today:

(1) selection of athletes

(2) urine sample collection procedure

(3) analysis of the A sample in an accredited IOC laboratory

(4) if the A sample gives positive analytical results, analysis of the B sample in the same accredited laboratory.

The hearing of the athlete is then organised by the medical commission, where the eventual sanctions against the athlete are decided.

International organisations have established a list of substance classes and methods that athletes are forbidden to use during competition and training. The latest list established by the World Anti-Doping Agency (WADA) ${ }^{19}$ for 2006 includes two types of steroid:

- the typically exogenous steroids, of which the main examples are given in fig 2

- the typically endogenous steroids-for example, androstenediol, androstenedione, dehydroepiandrosterone (DHEA), dihydrotestosterone, testosterone and related substances.

According to the 2004 WADA statistics, about $36 \%$ of the positive analytical finding declared by the accredited antidoping laboratories concerned anabolic-androgenic steroids. Among the 1191 positive cases, it is worth mentioning that testosterone and nandrolone were the most used substances (33\% and $29 \%$ of the cases, respectively). 
Testing for anabolic agents in the urine of athletes was implemented on a large scale during the 1976 Olympic Games in Montreal and was mainly based at that time on radioimmunoassay techniques. The techniques for the identification and characterisation of steroids and their metabolites in the urine have improved considerably during the past two decades. This improvement is largely due to the use of gas chromatography-mass spectrometry (GC-MS) techniques. Today, most anti-doping laboratories use techniques based on the solid phase extraction of the urine sample, followed by chemical modifications prior to GC-MS analysis. ${ }^{20}$ The confirmation procedure in an anti-doping analysis consists of demonstrating unequivocally that there is a correspondence between the GC and MS properties of the anabolic agent or its metabolite with those of an authentic pure standard or of a reference excretion study. ${ }^{21}$

\section{The $\mathrm{T} / \mathrm{E}$ ratio}

Detection of exogenous substances means identifying the parent compound or at least one metabolite. Nevertheless, with substances that are produced endogenously, such as testosterone, the presence of the substance alone cannot be considered to be an offence by itself. Moreover, a cut-off value for testosterone concentration cannot be used because of large observed interindividual and intraindividual urinary concentrations of the steroid. However, intake of testosterone causes characteristic changes in the pattern of steroids excreted in the urine. Based on studies of athlete populations, the IOC adopted in 1983 a ratio of testosterone to epitestosterone glucuronides ( $\mathrm{T} / \mathrm{E})$ with an authorised upper limit of 6.0 as a criterion for the administration of testosterone. Since epitestosterone is only a minor product of the metabolism of testosterone and does not increase after testosterone administration, the resulting effect is an increase in the T/E ratio..$^{22}$ In several studies, the distribution of results in Caucasian athlete populations shows generally a mean T/E ratio less than 2.0, ${ }^{20} 23$ whereas in Asian populations the mean T/E ratio is significantly lower. The IOC rules clearly indicate that a $\mathrm{T} / \mathrm{E}$ ratio greater than 6.0 constituted an offence unless there was evidence that this ratio is due to a physiological or pathological condition-for example, low epitestosterone excretion, androgen producing tumour, and enzyme deficiencies. ${ }^{24}$ In addition, it has been observed that hepatic metabolism of steroid hormones may be altered by administration of substances as ethanol with the resulting effect of modifying significantly the T/E ratio. ${ }^{24}$

Other urinary tests such as ketoconazole test ${ }^{25}$ and the testosterone glucuronide to luteinising hormone (T/LH) ratio $^{26}$ have been developed to deter doping with testosterone or a precursor. However, there is still a lack of a reference method for measuring and identifying $\mathrm{LH}$ and therefore the $\mathrm{T} / \mathrm{LH}$ ratio is less effective in meeting legal challenges. ${ }^{27}$ Detection of testosterone esters in plasma and hairs have been also suggested as promising solutions to deter doping with injectable preparations of testosterone esters. ${ }^{28} 29$ Nevertheless, doping controls are still limited on urine

\section{What is already known about this topic}

Anabolic steroids were added to the $1 O C^{\prime}$ s list of banned substances in 1975. Anabolic steroids are synthetic derivatives of testosterone, modified to enhance the anabolic rather than the androgenic actions of the hormone. Detection of substances that are not supposed to be produced by the body leads to an adverse analytical finding. Conversely, for the endogenous hormones such as testosterone or DHEA, it is mandatory to determine the origin of the steroid. samples for detection of doping with these substances. Regarding hair analysis, it has been found that these T esters are poorly stored in hairs and therefore only massive and repeated use of these substances may be detected in this biological matrix. ${ }^{30}$

Before a sample is declared as consistent with doping with testosterone or a precursor, further investigations are conducted, such as a longitudinal study of the urinary T/E ratio. As a first step, comparison with previous values should be done; if no previous values are available, several additional urine samples are analysed over a short period of time. This longitudinal study may represent a useful tool for discriminating the false positive (naturally elevated T/E ratios) results from those due to manipulation of the urine. ${ }^{23}$ According to guidance given by WADA in 2004, urine samples should be now submitted to isotopic ratio mass spectrometry (IRMS) if the $\mathrm{T} / \mathrm{E}$ is greater or equal to 4.0 and testosterone, testosterone metabolites, epitestosterone, and DHEA concentrations are greater than fixed cut-off concentrations. ${ }^{31}$

\section{Carbon isotope ratio}

Even if longitudinal study gives good quality information on the potential steroid profile manipulation, there is a lack of definitive proof for the exogenous application of natural steroids. One possible way of solving this problem is the ratio of the two stable carbon isotopes ${ }^{13} \mathrm{C} /{ }^{12} \mathrm{C}$, which can allow the differentiation of natural and synthetic steroids. As exogenous testosterone or precursors contain less ${ }^{13} \mathrm{C}$ than their endogenous homologues, it is expected that urinary steroids with a low ${ }^{13} \mathrm{C} /{ }^{12} \mathrm{C}$ ratio originate from pharmaceutical sources. ${ }^{32}$ Endogenous steroids are produced from cholesterol in the body. Cholesterol is derived from an average of a wide variety of feed vegetal and animal precursors or synthesised from precursors of feed origin.

In plant tissue, the main source of variation in ${ }^{13} \mathrm{C} /{ }^{12} \mathrm{C}$ isotopic ratio is derived from the different photosynthetic pathways for carbon dioxide fixation. Plants incorporate carbon dioxide via photosynthesis by three different mechanisms: the Calvin cycle $\left(C_{3}\right)$ pathway, the Hatch-Slack $\left(C_{4}\right)$ pathway and the crassulacean acid metabolism (CAM) pathway. The $\mathrm{C}_{3}$ pathway results in a large change in the carbon isotope proportions relative to atmospheric carbon dioxide and hence discriminates more strongly against the heavier isotope ${ }^{13} \mathrm{C}$ compared with the $\mathrm{C}_{4}$ pathway. Main representatives of $\mathrm{C}_{3}$ group are wheat, rice, potato, barley, grape, oats, and sugar beet, whereas maize, sugar cane, millet, and pineapple are the important species of the $\mathrm{C}_{4}$ group. ${ }^{33}$ The difference in the ${ }^{13} \mathrm{C}$ enrichment of food products in the diet and even in the food chain is caused by different contribution of naturally ${ }^{13} \mathrm{C}$-enriched constituents. Because maize, millet, and sugar cane $\left(C_{4}\right.$ plants $)$ are the common food ingredients in some areas of Africa, it is expected that the basic ${ }^{13} \mathrm{C}$ enrichment of the body store will be high for local populations. ${ }^{34}$ It is known that urine samples collected from a country such as Kenya have a higher content of ${ }^{13} \mathrm{C}$ in steroids than western or oceanian countries. ${ }^{35} 36$

The method for determining the isotopic composition of the relevant analyte includes gas chromatography, a subsequent combustion to $\mathrm{CO}_{2}$, and finally, mass spectrometric

\section{What this study adds}

Since 1975, several strategies and methods have been developed to deter doping with endogenous steroids. This review described these developments as well as the up to date procedures to be followed to prove administration of testosterone or testosterone prohormones. 
analysis of this gas in a special multi-collector mass spectrometer (gas chromatography/combustion/isotope ratio mass spectrometry, GC/C/IRMS). ${ }^{37}$ The ${ }^{13} \mathrm{C} /{ }^{12} \mathrm{C}$ value of testosterone or that of its metabolites will be measured and compared with that of urinary reference steroids within the sample to take into account variation in an athlete's diet. ${ }^{38}$ In addition, it should be emphasised that the ${ }^{13} \mathrm{C} /{ }^{12} \mathrm{C}$ value of these endogenous reference compounds should not be affected by steroid administration..$^{41}$ The result will be reported as consistent with the administration of a steroid if a significant difference is observed between the ${ }^{13} \mathrm{C} /{ }^{12} \mathrm{C}$ values of testosterone metabolites and the endogenous reference compound.$^{42}$ Following population studies, a different cut-off for positivity was stated in 2004 by the WADA Laboratory Committee. If the IRMS study does not readily indicate exogenous administration, the result should be reported as inconclusive, and if necessary further longitudinal studies are performed. ${ }^{31}$

It is also worth mentioning that an IRMS method for determining the ${ }^{13} \mathrm{C} /{ }^{12} \mathrm{C}$ values for urinary epitestosterone was developed to provide much needed additional support for the detection of doping with epitestosterone. ${ }^{43}$ Epitestosterone has no clinical use and is not available as a pharmaceutical. This compound is prohibited by sport authorities because its administration will lower the urinary $\mathrm{T} / \mathrm{E}$ ratio, a marker of testosterone administration. ${ }^{19}$

\section{CONCLUSION}

Although knowledge of androgen steroid metabolism has increased during the past decades and analytical guidance has been provided by sport authorities, detection of doping with testosterone remains a challenge in sport. Clearance of orally administered testosterone esters is rapid, and hence drug testing analysis of the urinary concentration can only be performed in the first hours after administration. ${ }^{42}$ In order to increase the sensitivity of testosterone esters detection, further investigations have to be conducted for identification of specific biomarkers of this class of doping agent. Beside the difficulty of their detection in urine samples, these substances are used for positive effects on mood states, and also to lower the level of fatigue.

\section{Authors' affiliations}

C Saudan, N Baume, N Robinson, L Avois, P Mangin, M Saugy, Swiss Laboratory for Doping Analyses, Institute of Legal Medicine, Lausanne, Switzerland

Competing interests: none declared

\section{REFERENCES}

1 Wynn V. Metabolic effects of anabolic steroids. Br J Sports Med 1975;9:60-4.

2 Milgrom E. Steroid hormones. In: Baulieu E-E, Kelly PA, eds. Hormones: From Molecules to Disease. Paris: Hermann, 1990:385-442.

3 Wilson JD, Griffin JE. The use and misuse of androgens. Metabolism 1980;29:1278-95.

4 Nieschlag E, Mauss J, Coert A, et al. Plasma androgen levels in men after oral administration of testosterone or testosterone undecanoate. Acta Endocrinol 1975;79:366-74.

5 Coert A, Geelen J, de Visser J, et al. The pharmacology and metabolism of testosterone undecanoate (TU), a new orally active androgen. Acta Endocrinol 1975;79:789-800.

6 Handelsman DJ. Androgen action and pharmacologic uses. In: DeGroot $\amalg$, Jameson JL, eds. Endocrinology.WB Saunders, Philadelphia, 2000:2232-42.

7 Janne OA, Palvimo JJ, Kallio P, et al. Androgen receptor and mechanism of androgen action. Ann Med 1993;25:83-9.

8 Mottram DR, George AJ. Anabolic steroids. Baillieres Best Pract Res Clin Endocrinol Metab 2000;14:55-69.

9 Kuhn CM. Anabolic steroid. Recent Progres Horm Res 2002;57:41 1-34.

10 Basaria S, Wahlstrom JT, Dobs A. Clinical review 138. Anabolic-androgenic steroid therapy in the treatment of chronic diseases. J Clin Endocrinol Metab 2001;86:5108-17.

11 Haupt HA, Rovere GD. Anabolic steroids: a review of the literature. Am J Sports Med 1984;12:469-84.
12 Hartgens $\mathbf{F}$, van Straaten $\mathrm{H}$, Fideldij S, et al. Misuse of androgenic-anabolic steroids and human deltoid muscle fibers: differences between polydrug regimens and single drug administration. Eur J Appl Physiol 2002;86:233-9.

13 Evans NA. Current concept in anabolic-androgenic steroids. Am J Sports Med 2004:32:534-42.

14 Blue JG, Lombardo JA. Steroids and steroid-like compounds. Clin Sports Med 1999;18:667-89.

15 Perry PJ, Andersen KH, Yates WR. Illicit anabolic steroid use in athletes. A case series analysis. Am J Sports Med 1990;18:422-8.

16 Rogol AD, Yesalis CE. Clinical Review 31. Anabolic-androgenic steroids and athletes: what are the issues, J Clin Endocrinol Metab 1992;74:465-9.

17 O'Connor DB, Archer J, Wu FC. Effects of testosterone on mood, aggression, and sexual behavior in young men: a double-blind, placebo-controlled, crossover study. J Clin Endocrinol Metab 2004;89:2837-45.

18 Baume N, Seiler R, Birrer D, et al. Evaluation of mood states following anabolic androgenic steroid oral intake combined with one month endurance training. Psychol Sport Exer (in press).

19 World Anti-Doping Agency. The 2006 Prohibited List. International standards. World Anti-Doping Code. Montreal: WADA, 2005, Available at:www.wada-ama.org/rtecontent/document/2006_LIST.pdf (accessed 19 September 2005)

20 Ayotte C, Goudreault D, Charlebois A. Testing for natural and synthetic anabolic agents in human urine. J Chromatogr B 1996;687:3-25.

21 Saugy M, Cardis C, Robinson N, et al. Test methods: anabolics. Baillieres Best Pract Res Clin Endocrinol Metab 2000;14:111-33.

22 Donike ML, Bärwald KR, Klosterman K, et al. Nachweis von exogenem Testosteron. In: Heck H, Hollman W, Liesen $\mathrm{H}$, et al. Sport: Leistung und Gesundheit. Köln, Germany: Deutscher Artze-Verlag, 1982:293-300.

23 Catlin DH, Hatton CK, Starcevic SH. Issues in detecting abuse of xenobiotic anabolic steroids and testosterone by analysis of athletes' urine. Clin Chem 1997;43:1280-8.

24 van de Kerkhof DH, de Boer D, Thijssen JHH, et al. Evaluation of testosterone/ epitestosterone ratio influential factors as determined in doping analysis. $J$ Anal Toxicol 2000;24:102-15.

25 Oftebro H, Jensen J, Mowinckel P, et al. Establishing a ketoconazole suppression test for verifying testosterone administration in the doping control of athletes. J Clin Endocrinol Metab 1994;78:973-7.

26 Kicman AT, Brooks RV, Collyer SC, et al. Criteria to indicate testosterone administration. Br J Sports Med 1990;24:253-64.

27 Carlström K, Palonek E, Garle M, et al. Detection of testosterone administration by increased ratio between serum concentrations of testosterone and 17 alpha-hydroxyprogesterone. Clin Chem 1992;38:1779-84.

28 Kintz P, Cirimele V, Jeanneau T, et al. Identification of testosterone and testosterone esters in human hair. J Anal Toxicol 1999;23:352-6.

29 Segura J, Peng SH, de la Torre X. Recent progress in the detection of the administration of natural hormones: special focus on testosterone. J Toxicol Toxin Rev 1999; 18:125-44

30 Segura J, Pichini S, Peng SH, et al. Hair analysis and detectability of single dose administration of androgenic steroid esters. Forensic Sci Int 2000; 107:347-59

31 WADA Technical Document. Reporting and evaluation guidance for testosterone, epitestosterone, T/E ratio and other endogenous steroids, 2004 Available at: www.wada-ama.org/ (accessed 30 May 2004).

32 de la Torre X, Gonzalez JC, Pichini S, et al. ${ }^{13} \mathrm{C} /{ }^{12} \mathrm{C}$ isotope ratio MS analysis of testosterone, in chemicals and pharmaceutical preparations. J Pharm Biomed Anal $2001 ; 24: 645-50$.

33 Platzner IT, Habfast K, Walder AJ, et al. Applications of isotope mass spectrometry. In: Winefordner JD, ed. Modern Isotope Ratio Mass Spectrometry. New York: J Wiley \& Sons, 1997:403-47.

34 Tanis AA, Rietveld T, Van Den Berg JWO, et al. Influence of the 13Cenrichment of the habitual diet on a $13 \mathrm{CO} 2$ breath test used as an index of liver glycogen oxidation: a validation study in western Europe and Africa. Nutrition 2000;16:6-10.

35 Cawley A, Rogerson J, Rahman K, et al. Preliminary results on the carbon isotope ratios of ketonic steroids in urine samples collected from different countries. In: Schänzer W, Geyer H, Gotzmann A, et al. Recent Advances in Doping Analysis. Köln: Sport und Buch Strauß, 2003:183-93.

36 Maître A, Saudan C, Mangin P, et al. Urinary analysis of four testosterone metabolites and pregnanediol by gas chromatography-combustion-isotope ratio mass spectrometry after oral administrations of testosterone. J Anal Toxicol 2004;28:426-31.

37 Brenna JT, Corso TN, Tobias HJ, et al. High-precision continuous-flow isotope ratio mass spectrometry. Mass Spectrom Rev 1997;16:227-58.

38 Aguilera R, Chapman TE, Starcevic B, et al. Performance characteristics of a carbon isotope ratio method for detecting doping with testosterone based on urine diols: controls and athletes with elevated testosterone/epitestosterone ratios. Clin Chem 2001;47:292-300.

39 Shackleton $\mathrm{CHL}$, Phillips A, Chang T, et al. Confirming testosterone administration by isotope ratio mass spectrometric analysis of urinary androstanediols. Steroids 1997;62:379-87.

40 Saudan C, Baume N, Mangin P, et al. Urinary analysis of $16(5 \alpha)$-Androsten $3 \alpha$-ol by gas chromatography/combustion/isotope ratio mass spectrometry: implications in anti-doping analysis. J Chromatogr B 2004;810:157-64.

41 Saudan C, Desmarchelier A, Sottas PE, et al. Urinary marker of oral pregnenolone administration. Steroids 2005;70:179-83.

42 Baume N, Saudan C, Desmarchelier A, et al. Use of isotope ratio mass spectrometry to detect doping with oral testosterone undecanoate: Interindividual variability of $\left({ }^{13} \mathrm{C} /{ }^{12} \mathrm{C}\right)$ ratio. Steroids 2006;71:364-70.

43 Aguilera R, Hatton CK, Catlin DH. Detection of epitestosterone doping by isotope ratio mass spectrometry. Clin Chem 2002;48:629-36. 